\title{
REFLEXIONES DEL DESARROLLO PEDAGÓGICO SOCIO-HUMANÍSTICO DE ESTUDIANTES EN PROCESO DE FORMACIÓN DOCENTE DE BÁSICA PRIMARIA'
}

\author{
TRAINING PROCESS \\ Por: : José Eriberto Cifuentes Medina² \\ Jaime Andres Torres Ortiz ${ }^{3}$ \\ Leidy Carolina Plazas Diaz ${ }^{4}$
}

REFLECTIONS OF THE SOCIO-HUMANISTIC PEDAGOGICAL

DEVELOPMENT OF STUDENTS IN THE PRIMARY BASIC TEACHING

Recibido: 23 de julio de 2019 - Aprobado: 13 de noviembre 2019

\section{RESUMEN}

El artículo pretende reflexionar sobre la importancia de los conocimientos socio-humanísticos en procura del rescate de la esencia de la academia, así como en la formación integral e idónea de estudiantes en proceso de formación docente de Educación Básica Primaria. El análisis parte de una revisión bibliográfica acerca de cuáles han sido las tendencias pedagógicas en el campo socio-humanístico que se han mantenido constantemente en las prácticas docentes, visibilizando allí dos vertientes del humanismo: uno clásico, neoconservador y romántico, el cual se basa en la formación por competencias, la práctica centrada en un currículo ya predefinido y las interacciones y relaciones que articulan contenidos tradicionales, los cuales están lejanos de las problemáticas latentes de las sociedades del conocimiento; y otro, poco frecuente, que se encamina hacia un humanismo liberador, emancipador y centrado en la libertad de los pueblos. Este último es el que nos interesa incentivar tanto en las aulas de clase universitaria en general, así como particularmente en el proceso de formación docente de estudiantes, con el fin de generar procesos democráticos y ciudadanos, así como espacios interculturales que

\footnotetext{
${ }^{1}$ Artículo de reflexión. Se deriva del proyecto titulado: Tendencias pedagógicas en el proceso de enseñanza y formación sociohumanística y ética en estudiantes de una licenciatura en Educación Básica con código SGI 2258.

${ }^{2}$ Investigador Asociado (I) SNCTeI, Convocatoria 833. Doctor en Educación, Universidad de Baja California-México. Magister en Educación, Especialista en Educación con Énfasis en Evaluación Educativa, Licenciado en Teología, Licenciado en Filosofía y Educación Religiosa, Universidad Santo Tomas. Integrante delgrupo de Investigación SIEK. Docente de la Licenciatura en Educación Básica con énfasis en Matemáticas, Humanidades y Lengua Castellana y Licenciatura en Educación Básica Primaria. Facultad de Estudios a Distancia, Universidad Pedagógica y Tecnológica de Colombia. joseeriberto.cifuentes@uptc.edu.co

${ }^{3}$ Doctor en Ciencias de la Educación, Magíster en Educación, Especialista en Desarrollo Humano, Psicólogo. Coordinador del grupo de Investigación SIEK, Categoría B - Colciencias. Docente de la Licenciatura en Educación Básica con énfasis en Matemáticas, Humanidades y Lengua Castellana. Director de la Escuela de Posgrados. Facultad de Estudios a Distancia. Universidad Pedagógica y Tecnológica de Colombia. Jaime.torres@uptc.edu.co

${ }^{4}$ Doctorando en Historia Universidad Michoacana San Nicolás De Hidalgo - México. Magister en Derechos Humanos, Licenciada en Ciencias Sociales. Universidad Pedagógica y Tecnológica de Colombia. Integrante del grupo de Investigación SIEK. Docente de la Licenciatura en Educación Básica con énfasis en Matemáticas, Humanidades y Lengua Castellana. Facultad de Estudios a Distancia, Universidad Pedagógica y Tecnológica de Colombia. leidy.plazas@uptc.edu.co
} 
permitan transformaciones de pensamiento necesarias para humanizar las sociedades de hoy.

Palabras clave: Desarrollo pedagógico, formación socio-humanística, estudiante, docente, básica primaria.

\begin{abstract}
The following article aims to reflect on the importance of socio-humanistic knowledge in attempts to rescue the essence of the academy, as well as the comprehensive and suitable training students in teacher training process. The analysis is based on a literature review about which ones the educational trends in the socio-humanistic field that have constantly kept in teaching practices have been. Two trends of humanism were identified: a classic, neo-conservative and romantic, which is based on competences, on the practice focused on a predefined curriculum and on the interactions and relationships that articulate traditional content which is distant from the hidden problems of knowledge societies. On the other side, there is an infrequent trend, which is heading towards a liberating, emancipatory and people freedom focused humanism. The latter is what we want to encourage both university classrooms and particularly, in the formation process of educators, in order to generate democratic and civic processes and intercultural spaces that allow transformations of thought necessary to humanize societies from today.
\end{abstract}

Key words: Pedagogical Development, socio-humanistic training, Student, Teacher, Primary

\title{
INTRODUCCIÓN
}

El presente artículo aborda investigaciones en los últimos tres años sobre las tendencias pedagógicas en la formación socio-humanística de estudiantes en formación inicial como Docentes Licenciados en Educación Básica Primaria que se desempeñarán posteriormente en los primeros grados del contexto educativo. Estas investigaciones abordan la formación de maestros en el campo de saber mencionado a través de diferentes referentes sociales, culturales y éticos.

Los aspectos más evidentes en estas tendencias pedagógicas refieren al orden intercultural y político que determina los modos de pensamiento, percepción y construcción de sentido sobre la formación socio-humanística y ética en un mundo globalizado e inmerso en múltiples condiciones problematizantes que afectan a toda la humanidad. Así mismo, el humanismo como enfoque epistemológico y filosófico, muestra importantes referentes conceptuales a tener en cuenta en los procesos formativos en la academia al igual que el planteamiento de las pedagogías críticas que determinan la formación del sujeto para el ejercicio en el campo de la educación como licenciado en Educación Básica Primaria.

Los procesos de formación de los licenciados en Educación Básica Primaria se enfocan en la actualidad en una acción integral orientada hacia el desarrollo humano, sus cualidades éticas, 
morales, espirituales, sociales y culturales para el ejercicio en campo de la educación. Todas estas integradas a una práctica educativa caracterizada por la formación en competencias, la práctica centrada en un currículo ya predefinido y las interacciones y relaciones que articulan contenidos tradicionales, lejanos de las problemáticas latentes que aquejan a una humanidad en crisis.

Por lo anterior, una de las formas de recuperar y desarrollar el sentido social de la academia tiene que ver con los conocimientos socio-humanísticos que se puedan cultivar en los estudiantes, especialmente en los que se encuentran adscritos a programas de formación docente, los cuales también serán relevantes en su formación personal. No obstante, la tendencia pedagógica tradicional muestra una formación instruccional que se sustenta en la condición mercantilista y por competencias para un ejercicio de la práctica educativa centrada en el producto. Frente a lo anterior, se habla de la formación de estudiantes en los programas de licenciaturas, que tienen -entre otras- la gran responsabilidad de poder formar generaciones con sensibilidad para el sentido de lo humano, atendiendo a la experiencia crítica y transformadora de los entornos sociales.

Este texto contará con cuatro apartados. En la primera parte se abordan los objetivos de formación socio-humanística en general, analizando algunos estudios que aportan elementos conceptuales para la compresión de esta y su importancia en la formación de estudiantes universitarios; seguidamente se aborda la formación socio-humanística y ética desde una mirada crítica, que ilustra a los estudiantes en las problemáticas sociales y culturales que aquejan a las sociedades hoy día con el fin de generar procesos de concienciación desde el ejercicio pedagógico.

En una tercera instancia se analizan los momentos anteriormente mencionados en el campo socio-humanístico y ético como aspecto fundamental para promover el crecimiento personal, el desarrollo humano y el pensamiento crítico; es decir, como eje dinamizador para formar ciudadanos idóneos y coherentes en el contexto de las situaciones sociales, culturales y educativas actuales, así como, en las que tengan que enfrentar en su ejercicio docente, visibilizando allí dos vertientes del humanismo, uno clásico, neoconservador y romántico, hacia un humanismo liberador, emancipador y centrado en la libertad de los pueblos.

\section{Generalidades de la formación socio-humanística}

Los objetivos de formación de licenciados en educación a través del campo del saber de las ciencias sociales, humanística y ética, enmarca una tendencia caracterizada por la comprensión general de la condición humana en el mundo, a través de los espacios de la globalización, las crisis sociales y políticas y, las migraciones entre naciones desarrolladas y aquellas inmersas en el subdesarrollo y los conflictos entre seres humanos de diversa índole.

Se considera pertinente abordar aspectos éticos, valorativos y socioculturales que implican el aprendizaje de emociones y apropiación de los ideales del humanismo como eje central de las 
prácticas formativas en un mundo diverso, interétnico, intercultural, pero en una tensión y flexión continua de problemáticas latentes como las guerras religiosas y políticas, las migraciones sociales producto de estas guerras, el desplazamiento forzado, la xenofobia, la pobreza en naciones en donde los recursos vitales son escasos y con altos niveles de corrupción, entre otras, aspecto como la inclusión de estos campos del saber en el Programa de Licenciatura en Educación Básica Primaria.

A su vez, la formación de maestros o docentes que posteriormente van a enseñar en ambientes escolares de Básica Primaria se ve afectada por las políticas sociales y educativas que determinan los contenidos curriculares y las estrategias pedagógicas y didácticas a seguir, a través de la cuales se privilegia la formación en el dominio del concepto teórico propio de la disciplina y el distanciamiento de la formación humana que abordan temas propios de la condición del sujeto como ciudadano, ética y moralmente reflexivo para generar críticas, diálogos compartidos y consensos para proponer soluciones.

Según Lutsan (2013),

"la formación en un ambiente multicultural caracterizado por la diversidad de pensamientos, creencias y estilos de vida entre otros, implica la proyección y sensibilidad humana para compartir y reconocer tradiciones especiales, diferencias en los modos de vida, las orientaciones sexuales y los valores culturales de personas que comparten un mismo espacio vital"

Una formación en este sentido es de orden interétnico y dialógico, y se caracteriza por la capacidad para comprender al otro en las relaciones entre sujeto y sujeto. La formación a través de la interrelación cultural y de valores posibilita enriquecer la perspectiva del otro bajo los principios del humanismo clásico.

Lo anterior, no solo surge en el ámbito de la formación en los primeros años de la básica primaria, o primeros años de formación, también se observa en los procesos de formación en la educación superior universitaria, en donde se observa actualmente el alejamiento a incluir en el currículo, las asignaturas de ética, humanidades y sociales, en especial, para los diferentes programas de formación profesional; estas asignaturas se reducen a didácticas específicas o de ciertas disciplinas, producto del afán por formar en el dominio de un conocimiento y no en el dominio y conocimiento de sí mismo y, de la comprensión del otro.

Al respecto Quintana (2009) afirma que "la base humanista que constituyó el fondo sobre el cual se edificaba la formación intelectual de la población culta y profesional de los países occidentales se está hundiendo". Este punto de vista se ve reflejado en cómo los planes de estudio de Educación Básica y Media se van despojando de los contenidos humanistas, y en la Educación Superior las facultades de Filosofía y Lenguas Clásicas se van quedando sin alumnos, lo cual denota un hecho 
irreversible a causa del desarrollo industrial y material de la sociedad.

La preocupación a nivel latinoamericano es generalizada y, se observa la tendencia a cerrar más programas en humanidades como lo han manifestado diferentes países desarrollados, sea este el caso del mismo Ministro de Educación de Japón o las intenciones de la Universidad Complutense de Madrid en España, en donde la formación socio-humanística representa muy poco interés para los fines de formación de estas naciones.

Sin embargo, aunque sean muchos los interesados en desplazar a las humanidades de los planes de estudios, muchos otros son defensores están plenamente convencidos que es imprescindible que los profesionales se formen en el pensar, sentir, actuar, saber, hacer, siendo posible además la articulación entre el saber humano y el conocimiento técnico, así como, la formación en lo moral, afectivo, cognitivo y existencialista (Aloni, 2013). Entre otras virtudes, sin ellas sería imposible la comprensión de las consecuencias humanas en periodos de cambios sociales cada vez más frecuentes en la tensión y crisis, en los que nos enfrentamos a fenómenos complejos viéndose vulnerado todo ser humano en sus diversas facetas.

Por lo anterior, la presente revisión al estado del arte evidencia algunos trabajos investigativos y reflexivos que permiten establecer el sentido y la importancia de rescatar en el espacio curricular la formación socio-humanística y posicionarla en los claustros universitarios. Se reconoce que el éxito o no del acto educativo se debe, en gran parte, a las tendencias pedagógicas del docente universitario que se encuentre a cargo del proceso pedagógico socio-humanístico de los estudiantes. De acuerdo con Soto (2009) "el docente universitario desde la libertad de pensamiento repensará la sociedad y replanteará conceptos que modifiquen cambios de conductas siempre dentro de los valores éticos ciudadanos de la comunidad”.

En la formación de valores éticos y ciudadano, se requiere más que vocación por parte de la persona que decide formarse como licenciado o maestro. Es decir, se necesitan de ciertas habilidades que le permitan responder a problemáticas sociales inmediatas, comprender sus dinámicas y las formas como se debe actuar en ella, es decir, un perfil flexible, crítico, promotor de cambios con capacidad para convivir en una sociedad multiétnica, globalizada, orientada a diálogos que empoderen una educación humanística, basada en una ética colectiva que permita a los profesionales estar al servicio de una sociedad y en beneficio de una comunidad (Gutiérrez Girardot, 1986), (Marcano y Reyes, 2007), (Aloni, 2013).

Este beneficio de colectividad y comunidad se asocia a su vez a las investigaciones propuestas por Lutsan (2013) citando a B. Bojchenko (2006), quien comenta que la formación ética y socio-humanística se enfatiza en la multiculturalidad y se considera como un proceso de formación sistemática y deliberada del desarrollo filosófico, de creencias y sentimientos del individuo y su 
proyección en comunidad. La formación ética y socio-humanística se basa en el reconocimiento de la diversidad cultural, con el enriquecimiento de los sentimientos a través de la relación especial con las demás personas y con el mundo, en un diálogo pedagógico continuo (Aloni, 2013). Así, estos académicos definen algunos criterios de formación:

En lo cognitivo se refiere al conocimiento sobre la existencia de las relaciones humanas, normas y reglas morales, su significado y esencia, seguir sus propias vidas, entendimiento de la naturaleza y condiciones del comportamiento cultural, proyección y comunicación, la habilidad para acceder a los hechos de la realidad en términos del todo como un conocimiento de los aspectos que la definen.

En lo actitudinal se refiere a que las actitudes, valorativas, emocionales y, moralmente positivas que gobiernan las relaciones entre las personas, conllevan a interactuar, aumentar el deseo de seguirlas a través de la identificación de las mismas y su aprecio por el aprecio por las cualidades personales que son apropiadas para la proyección de vida, de los valores consigo mismo y con los demás en lo concerniente al respeto, reciprocidad emocional y el desarrollo mental y emocional del ser humano.

En las actividades de reglas de comportamiento cultural, capacidad para interpretar falsas manifestaciones y posibles violaciones basadas en el conocimiento teórico y los juicios emocionales valorativos sobre estas manifestaciones, así como la habilidad para construir comunicaciones dialógicas entre sujetos, aplicar tácticas para prevenir conflictos y construir soluciones conjuntas (Lutsan, 2013).

Según Lutsan (2013), la formación multicultural con fundamentos socio-humanísticos se enfoca en varios principios éticos y morales que se deben tener en cuenta, estos son: Educación para la dignidad humana y alto nivel de carácter moral y educación para la coexistencia de diferentes grupos sociales, razas, religiones, grupos étnicos, tolerancia, cooperación mutua. La superación de los sistemas educativos dominantes, que intentan imponer normas y principios sociales cerrados y sesgados, deben ceder ante las capacidades adaptativas entre grupos sociales que deben coexistir entre sí. Debe haber una conciencia de la diversidad cultural para la auto-identidad, actitudes positivas y educativas orientadas hacia una cultura basada en las diferencias, habilidades de interacción basadas en tolerancia y entendimiento.

Otros referentes educativos para la formación socio-humanística son: la educación en etnopedagogía y etnopsicología. Estos referentes incluyen la sensibilidad emocional activa, el balance psicológico y la tolerancia, la apertura a la empatía, la creatividad y reflexividad, la autoestima y la habilidad para la autoconciencia, todas estas forman una nueva posición social, el desarrollo de una actitud de auto-responsabilidad como persona y la habilidad para comunicarse con otros en un continuo de interacción y relación social (Lutsan, 2013). 
De igual forma, Marcano y Reyes (2007) proponen seis dimensiones en la formación socio-humanística del licenciado: disciplinar, metadisciplinar, pedagógica, heurística, personal y sociocultural, las cuales apuntan a una educación holística. No obstante, se resalta unas dimensiones más que otras con el fin de relacionarlas directamente con la formación socio- humanística, las cuales permiten concientizar a la comunidad académica acerca de las mejoras que se deben realizar desde el quehacer pedagógico para lograr la idoneidad del ejercicio docente y encaminar la formación del estudiante como ser social, digno, autónomo y potenciado en su capacidad de diálogo para promover su individualidad en relación con la sociedad (Aloni, 2013).

Haciendo referencia al aspecto sociocultural según Soto (2009) la formación socio-humanística va de la mano con la interculturalidad y este es uno de los grandes retos socioeducativos y profesionales en el siglo XXI. La dimensión sociocultural es por ende relevante en la formación socio-humanística, contemplándola como la posibilidad de los educadores de transformar los contextos sociales contribuyendo de esta manera a generar cambios en las relaciones sociales. Siguiendo a Marcano et al. (2007), se busca mayores niveles de participación ciudadana, reduciendo los niveles de marginalidad y exclusión (Marcano, et al. 2007). Desde esta perspectiva, se propende por la formación de mejores ciudadanos y para ello, es innegable el cambio en valores y actitudes que demandan las nuevas sociedades y los diversos contextos a los que se enfrenta el ser humano.

Uno de los grandes inconvenientes que se presentan en el proceso de enseñanza y aprendizaje de la socio-humanística tiene que ver con la resistencia a nuevas formas de enseñanza, a la necesaria indagación de fuentes de información y la capacidad de construcción de conocimiento. Una dimensión integral como la heurística propende por el aprovechamiento de las múltiples potencialidades de los educandos a partir de la motivación del docente, para que ellos se aproximen a la comprensión objetiva y holística de la realidad y de esta manera, intervenir en su transformación (Correa, 1997).

Si se parte de los intereses de los estudiantes, de sus inquietudes frente al mundo y se involucran en él como sujetos políticos garantes de derechos, se encontrará un sinnúmero de herramientas que posibilitarán una formación integral y la construcción de ambientes escolares propicios para la socio-humanística. Las asignaturas de arte por ejemplo, además de ofrecer múltiples posibilidades para la comprensión de temáticas, juegan un papel importante especialmente en el desarrollo de la ciudadanía, generando procesos de sensibilización, participación, organización, representación y reconocimiento ciudadano. Las artes favorecen dinámicas de integración escolar, social y cultural, mediante propuestas relacionadas con el fomento de actitudes para la tolerancia, la solidaridad y la convivencia creativa que promuevan una conciencia crítica frente a los mecanismos de exclusión social, y convertirse, a la larga, en un proceso consciente de crecimiento individual y colectivo (Abad, s.f). 
No es suficiente con poseer estrategias didácticas para responder a necesidades y motivaciones de los alumnos, se debe tener un conocimiento profundo de los saberes teóricos para poderlos articular en la práctica. Por lo tanto, se ha contemplado la dimensión disciplinar de los diversos saberes como un componente a reforzar en los procesos educativos de los estudiantes, siempre y cuando se entienda que la profundización teórica y conceptual es esencial y trascenderá únicamente si se relaciona con la realidad y con el significado de lo humano (Ruiz Mendoza, Álvarez Aguilar \& Pérez Ramírez, 2008) para así poder generar pensamiento.

En este aspecto, Hugo Zemelman (2005, p. 65) se refiere a un desajuste entre teoría y realidad, por lo que plantea una resignificación de la teoría a la luz de las exigencias de las realidades históricas, muchas veces emergentes, nuevas, inusitadas, imprevistas. Quiere decir que no basta con tener los conceptos y construir discursos cerrados, que conlleva a generar un pensamiento que se entiende como una postura, como una actitud que cada persona es capaz de construir a sí misma frente a las circunstancias que quiere conocer situaciones que tenga que enfrentar en lo que refiere a la formación de licenciados en Educación Básica Primaria. Además, el afán de rescatar los saberes disciplinares tiene que ver con problemas conceptuales y desarrollo del lenguaje oral, expresivo y escrito que se ha de mantener en equilibrio con la formación socio-humanística.

Teniendo claros los criterios de formación y las dimensiones para el proceso de enseñanza y aprendizaje del saber socio-humanístico, se trae a colación de igual forma, la necesidad de dar a conocer a los estudiantes las problemáticas sociales actuales como complemento en el proceso pedagógico y como mecanismo de concienciación que incida en la activación de emociones, sentimientos, pero también de razonamientos que los profesores generen en los educandos lecturas críticas, reflexivas y propositivas de su entorno y del entramado social en general.

\section{La comprensión de las problemáticas sociales y culturales como tendencia pedagógica para la formación socio-humanística}

Una tendencia pedagógica crítica parte de la situación histórica en un contexto ligero, flexible e incierto, una sociedad sin orden que trasciende a la condición humana (Bauman, 2003) con cambios apresurados, los cuales, pareciera, se hacen cada vez más difíciles de explicar y de comprender. Las tendencias pedagógicas de un sector docente que se rehúsa a cambiar sus prácticas pedagógicas y se anclan en las mismas temáticas y métodos de enseñanza, convirtiéndose en una tarea rutinaria (Pineda, 2010), poco innovadora y atractiva para las generaciones de las sociedades del conocimiento o sociedades en red en plena era de la información (Castells, 2005).

Está claro que el campo de la socio-humanística desarrollaría la comprensión holística y objetiva de la realidad de los educandos y de la que tienen que asumir en su rol como docentes. Un aspecto que incide en estos procesos sociales y culturales de cambio es la dinámica globalizadora que sustenta la intervención abierta de diferentes formas de culturización. Para fomentar los procesos de 
interacción cultural y social diversa con sentido de identidad, se proponen los ideales del humanismo como una tendencia pedagógica que sustenta los procesos educativos basados en la seguridad social y la apertura a modos de vida libres de conflicto; estos aspectos se soportan en los modelos interculturales que han determinado la educación moderna.

Sin embargo, la tendencia educativa actual está en rechazar la tradición pedagógica de las culturas como resultado de una negación del humanismo, producto de las homogenizaciones de los procesos educativos que traen consigo la pérdida de significado de las identidades individuales de orden cultural. Por consiguiente, las expectativas sociales y el dominio de las culturas dominantes se imponen sobre las socio-culturales que promueven la identidad y confianza por aquellos valores y principios de la dignidad de una comunidad.

Estos aspectos sobre la dignidad humana son abordados por Morova et al (2015), como una característica de la tradición pedagógica basada en la formación integral, en la cual, las creencias sociales y culturales son parte importante en una educación centrada en promover valores humanos. Sin embargo, en los países con una gran diversidad étnica y cultural se presenta un cambio en los procesos de formación en donde los valores, principios axiológicos de la convivencia y la misma identidad requiere de una fundamentación de lo etno-cultural e histórico-cultural para dar identidad al concepto dignidad humana como elemento transversal al currículo.

De igual forma, Rivera \& Polonia (2013) sostienen que "la formación humanística, política y ética no compete necesariamente a ciertas instituciones ni a una asignatura en particular, como tampoco a un profesor o un momento definido en clase". En realidad, es un asunto que ha de preocupar y requiere involucrar a toda la sociedad en el campo pedagógico de la transversalidad curricular, por lo que es deseable evitar su fragmentación y procurar su articulación o su permanencia con el currículo oculto. La transversalidad y relevancia de la formación socio-humanística en el campo social, profesional y personal del licenciado en Educación Básica Primaria, ha de llevar a una incorporación efectiva en el proceso educativo y la integración de los aprendizajes fundamentales para la vida.

Afirma Quintana (2009) que el reto de la formación socio-humanística ante las tendencias en contra de integrar asignaturas de humanidades en los currículos y en la educación, se "ha originado hace unas décadas y es cada vez más intensa y extensa, notándose especialmente en la Enseñanza Superior. Esto se ha concretado y manifestado en los documentos de la Unión Europea, máxime en la Declaración de Bolonia, que es considerada como el documento de consolidación de este movimiento". Se pretende que los estudiantes se formen en habilidades, actitudes y competencias y no solo en conocimientos.

El ideal de la formación humanística está unida a la educación en la formación, proyección y 
promoción de un hombre mejor para la sociedad como ideal soñado, por lo tanto, el humanismo enseña a los estudiantes-maestros a ser críticos, constructivos y propositivos en los conocimientos que reciben y construyen. Estos aspectos mencionados son recordados a partir de la perspectiva clásica griega proyectada en los planteamientos de Platón (1991), que citado por Quintana (2009), en el Protágoras:

"Pone en guardia contra las enseñanzas de los sofistas, pues en la compra de la sabiduría no ocurre como en las demás compras, ya que la ciencia no se la lleva uno en una vasija: una vez pagado su precio, es preciso llevársela en uno mismo, ponerla en la propia alacena, y así, cuando uno se va, el bien y el mal están ya hechos”.

La educación de base humanista se proyecta en el aquí y ahora y por ello el profesor ha de poner los conocimientos con fuerza transformadora al servicio de la educación y formar mediante ellos a los verdaderos licenciados, del mismo modo que el alfarero modela su arcilla y el escultor sus piedras, se trata de contribuir en uno y otro a la proyección y transformación de la realidad problemática en un escenario posible de construcción del tejido social y humano.

En este sentido Quintana (2009), sostiene que la Pedagogía Humanista no solo es punto de partida sino también objeto indeclinable de la formación socio-humanística del licenciado, la cual debe basarse en:

"Los valores que hacen a los hombres más humanos: la justicia, la virtud, la libertad, la adaptación, la creatividad, la bondad, el amor, la auto superación, la apertura, el diálogo, la actividad, la comprensión, la energía, la esperanza, la tolerancia y la colaboración. El humanismo es un ideal humano muy serio y difícil, pero vale la pena luchar por él, pues es, para el hombre, una garantía de su calidad humana" (Pág. 228)

La pedagogía humana y la formación socio-humanística han de proponer y promover una buena educación en valores a los educandos en el nivel superior y a la vez de ellos en los niños; para que se consolide una buena educación humana desde la infancia y pueda comprender las problemáticas sociales y culturares de cada entorno educativo de cual hacen parte los sujetos del acto educativo.

\section{La formación socio-humanística en la educación superior}

La formación socio humanística en la educación superior ha de prevalecer en el currículo de la formación de los licenciados en la medida que contribuye a dignificar al ser humano, como eje central y ethos de la educación de la cual es objeto el sujeto humano, por ello:

"[...] entre más irrelevante se hace para una estructura académica, enseñar a través de las humanidades, más evidente se hace que la universidad carece de una estructura. No es extraño, por lo tanto, que los desenlaces del proceso educativo en Colombia no contribuyan a la investigación y a la creatividad, sino que se conviertan en productos no reflexionados, 
respondiendo más a la lógica de eficientísimo y de certificación de competencias, de cumplimiento de metas, pero cuya naturaleza es extraña al docente y a sus estudiantes" (Urrea; 2015 en www.cronicadelquindio.com).

La formación socio-humanística ha de contribuir a la hermenéutica antropológica de la existencia en la medida que el hombre puede darse a sí mismo su propio ser; en este sentido "el hombre es biológicamente un ser de la naturaleza que debido a superposición de su ser trasnatural es programable en alguna escala en el ámbito social y en la esfera individual, con las ambiciones, las necesidades, la esperanza, la planeación, las luchas, los esfuerzos"

Es preferible que la enseñanza de los saberes socio-humanísticos incida e impacte en la formación académica, humana y profesional del licenciado en educación básica primaria. Para el humanismo, el mundo es el mundo del hombre; la naturaleza es mediada, transformada, designada y puesta a cumplir funciones. El mundo social es puesto por el hombre en la medida en que actúa en la naturaleza e interactúa con los demás, todos inmersos en la sociedad.

Para comprender la educación socio-humanística en la universidad, es pertinente entender los postulados de autores como Claudio Bonvecchio, Martha Nussbaum y Jaques Derrida, quienes;

[...] "han aportado desde la filosofía algunas luces que, bajo el lente de la crítica y de la propuesta alternativa, podrían ubicar mucho al imaginario social universitario respecto al sentido de la educación humanística en la universidad, asunto que también es de la incumbencia de los profesores y estudiantes que no reconocen en el campo de dicha educación, pro in situ son humanos, es decir, no son humanoides" (Camargo, 2012)

En este sentido, la Universidad,

"es real, librepensadora, autónoma, es también reconocerla como un campo de lucha por la democracia y los derechos humanos, contra la imposición de modelos que convierten en mercancía toda relación humana, por la resistencia en derecho, por la sostenibilidad del medio ambiente, etc.; también reconocerla y en esto considero que están las bases de su educación humanística y apropiarla como campo plural de conocimientos..." (Camargo, 2012).

Es necesario reconocer como eje fundamental en la educación universitaria la formación socio-humanística de los licenciados en pro de consolidar la fuerza connatural del desarrollo de los principios epistemológicos del reconocimiento como ser humano. Los estudiantes universitarios de la licenciatura en Educación Básica Primaria en Colombia, han de formarse como maestros y como excelentes seres humanos y desde luego idóneos en la profesión que han elegido como parte de su proyecto de vida y consientes del servicio con calidad que tendrán que ofrecer a su comunidad. En este sentido, García (2014) afirma que el docente está mejor preparado y canaliza sus esfuerzos para ir construyéndose como un intelectual, además que: 
"Podrá abordar los temas de contenido humanístico o los que le correspondan, desde un ángulo de mayor pertinencia, objetividad y convicción; igualmente si exhibe en su práctica docente un buen dominio de las diversas estrategias para comunicar tal saber, sin duda tendrá más posibilidades de alcanzar los objetivos académicos propuestos, haciendo que tales cátedras vayan perdiendo el estigma de "ornamentos inútiles". (pág. 127)

Para un programa académico, es relevante a nivel curricular que los estudiantes y profesores vayan en busca del sentido de las cátedras de contenido humanístico, pues las discusiones que se propongan en torno a este servirán no solo para aproximarse aún más a su compresión sino también a su proyección en términos de lo humano y lo humanizante; a fin de re-significar las cátedras de desarrollo humano y socio humanística desde la ética del cuidado de sí y de los otros para fortalecer la construcción del tejido social en la formación universitaria y en el ejercicio profesional como licenciado en Educación Básica Primaria.

En los procesos de interacción de la educación superior, la formación socio-humanística ha de permear en los estudiantes en su preparación personal y profesional para el ejercicio de la docencia; desde el escenario de la consolidación de los valores, dando inicio por la identidad universitaria, al respecto Molina (2015) sostiene:

"Ya en el ámbito de la Educación Superior, se entiende entonces la identidad universitaria como un sentimiento de pertenencia, una identificación a una colectividad institucionalizada, según las representaciones que los individuos se hacen de la realidad social y sus divisiones, y en donde se alinean factores tales como la experiencia escolar pasada, la pertenencia, las relaciones humanas, la percepción de la universidad como unidad, el territorio, las afinidades, la educación, el vínculo, las normas y la dificultad del ingreso a la institución" (Pág. 206)

En los factores que intervienen en el desarrollo de la identidad de estudiantes universitarios en formación y proyección para el ejercicio de la docencia, es conveniente que se resignifique la misión de ser maestro desde la Pedagogía Humanista, en cuanto a: "la responsabilidad de todos los actores educativos y que se debe caracterizar por la concepción de ser humano, sociedad y educación que se tenga” (Rivera \& Polonia; 2013, 77)

\section{La formación socio-humanística: sinónimo de formación ciudadana}

Hemos contemplado la educación en ciudadanía como una de las premisas del proceso socio-humanístico de los estudiantes en cualquier nivel educativo, principalmente en los que se preparan para responsabilizarse de las generaciones en edad escolar donde será más fácil, desde un nivel temprano, inculcar el respeto por la diferencia, la multiculturalidad y prepararlos para una ciudadanía local y universal. Los aportes de Nussbaum (2010), en lo que ella denomina "educación para la ciudadanía democrática”, contribuyen significativamente en el saber socio-humanístico de los estudiantes en cuanto a aptitudes que les permitan "reconocer a las demás personas con los mismos derechos que uno, aunque sean de distinta raza, religión, género u orientación sexual y 
de contemplarlos con respeto, con fines en sí mismos y no como medios para obtener beneficios" (Pág. 48). Para Carvajal Barrios (2013), este modelo de educación le asigna valor a:

"La dignidad humana, la libertad, la igualdad, la justicia social, la comprensión, el respeto, el interés genuino por los demás, la equidad de género, la creatividad, la imaginación empática, la dupla recíproca razón-compasión, la cooperación, el pensamiento crítico (así como la habilidad y el coraje de expresarlo), el sentido de la responsabilidad individual y la curiosidad en el marco del respeto y la comprensión" (Pág.79)

Otro de los objetivos de la orientación socio-humanística articulados con la ciudadanía conducen a una formación para la universalidad. En este sentido, Nussbaum al hablar de ciudadanía mundial conmina a abarcar los aportes de la historia, la geografía, el estudio interdisciplinario de la cultura, la historia de los sistemas jurídicos y políticos, la economía global y el estudio de la religión (Pág. 122), permitiéndole al estudiante un conocimiento suficiente y real de las actividades humanas.

Por lo anterior, se considera a la historia entre los saberes disciplinares que son transversales y que proporcionan elementos claves para la comprensión de la realidad, la interpretación de los actos humanos en diferentes contextos y situaciones y resignifica el concepto de ciudadano. La interpretación de Concepción Arias y Simarro (2008) acerca de la importancia de estudiar historia parece oportuna para el saber socio-humanístico y la formación ciudadana, puesto que ella argumenta que:

"Es de gran valor para la persona y para la sociedad saber historia porque ofrece la posibilidad de ser libre, y por tanto, responsable, ya que facilita el despertar de la conciencia trascendente: de estar en un tiempo y en un espacio limitados, al reconocer el compromiso personal y social, al observar en los acontecimientos que todo hecho tiene causas y consecuencias de modo sistémico. Permite desarrollar la capacidad de observar los sucesos desde "afuera" (a la vez que me observo como observador) e invita a reflexionar sobre la relatividad de la vida y a reconocer lo que es esencial”. (Pág. 5)

En este mismo sentido Savater (2010) afirma que "es importante que no se pierda, no minimice la consideración histórica en nuestros aprendizajes básicos, aunque comprender la historia sobre todo en sus aspectos políticos e ideológicos sea mucho más difícil que memorizarla" (Pág. 140). Al igual que hace fuerza en la enseñanza de la historia desde las narraciones de los estudiantes y sus comunidades contada por quienes pertenecen a ellas, ahora se propone practicar lo contrario, la historia como hagiografía colectiva; hay que recobrar el sentido de la historia que aparte de ser amena y parte del ser humano favorece la comprensión humana del hombre.

En perspectiva de Rivera \& Polonia (2013), señalan que algunas pedagogías contribuyen a la formación humanística como: la pedagogía humanista, la pedagogía del amor, la pedagogía de la abnegación, la pedagogía del trato diferencial y de la ejemplaridad; permiten vislumbrar que un 
maestro comprometido y apasionado contagia con su discursos a sus estudiantes y ellos captan si su profesor ama lo que hace y perciben su entrega generosa, "El disfrute de la misión despierta sensibilidades, abre horizontes, ilumina caminos, haciendo viable que se despierte el deseo de crecer intelectual, afectiva y profesionalmente” (Pág. 86). Vivir con pasión la misión de educar es mostrar las bases de humanización y fortalece la esencia del ser maestro en su formación socio-cultural, heurística y disciplinar.

\section{A manera de conclusiones}

Los aportes brindados por las investigaciones muestran la necesidad de resaltar que en Colombia, la formación socio-humanística, más allá de ser una asignatura de relleno curricular como suele denominarse comúnmente entre la comunidad académica, subestimando su alcance e incidencia en la formación de licenciados en Educación Básica Primaria.

Uno de los afanes de las tendencias pedagógicas en este campo es el de promover valores sociales, culturales y antropológicos centrados en la convivencia y la democratización de los estilos de vida, inclusión y participación en todos los ámbitos sociales, políticos y económicos que definen a las sociedades y a la educación.

De esta manera, el conocimiento educativo cultural y de la formación socio-humanística no es suficiente para lograr centrar la mirada en la calidad ética y profesional con la que los egresados profesionales en diferentes ciencias de la educación salen al campo a laborar. Es de anotar que son las humanidades las que siguen permeando en la conciencia social, cultural y de reciprocidad emocional entre los ciudadanos, con lo cual de ellos se resiste a desaparecer de una sociedad que, aunque no se reconozca públicamente, ha logrado algunos cambios en materia de cultura para la paz, la convivencia, el sentido del otro y la necesidad de incluir la diversidad como parte de su condición como nación. Avances en materia de derechos civiles, de políticas públicas para poblaciones vulnerables, protección del medio ambiente, fomento al desarrollo sustentable, respeto por las diferencias, inclusión, educación intercultural, entre otros, son temáticas abordadas casi que exclusivamente en este campo.

Dado que el ejercicio de la docencia de la socio-humanística a lo largo de la historia se ha caracterizado por ser profesión de vocación y que ha contribuido de manera efectiva en lo que a formación integral del ser humano se refiere, la formación socio-humanística se constituye en un reto en la educación superior por la importancia inminente en las demás disciplinas del saber; es un desafío imperante captar la atención de los estudiantes en formación como profesores e impulsar mayores iniciativas para abrir vías que impulsen a la sociedad hacia la formación de la sensibilidad como apuesta de la formación para una sentido humano en continua evolución y adaptación a las realidades propias del ser humano. 


\section{REFERENCIAS BIBLIOGRÁFICAS}

Abad, J. (s. f). Usos y funciones de las artes en la educación y el desarrollo humano. En: Jiménez, L., Aguirre, I. \& Pimentel, L. (Ed.), Educación artística, cultura y ciudadanía (17-25). Madrid: Fundación Santillana. Recuperado de: file://C:/Users/user/Downloads/EDART2.pdf

Aloni, N. (2013). Empowering Dialogues in Humanistic Education. Institute for Progressive Education at Kibbutzim College of Education. Educational Philosophy and Theory. Vol. 45, No. 10, 1067-1081. Recuperado de: http://dx.doi.org/10.1111/j.1469-5812.2011.00789.x

Arias y Simarro, C. (2008). ¿Cómo enseñar la historia? Técnicas de apoyo para los profesores Guadalajara: ITESO.

Bauman, Z. (2003). Modernidad líquida. México: Fondo de Cultura Económica.

Camargo, M. (2.012) "Una propuesta de educación humanística para un colectivo de humanos y no humanos". Seminario Permanente de Pedagogía. Revista de la U.P.T.C. Tunja, 4 N 4: 9 - 38 [2012].

Carvajal, G. (2013). Educación significa educación para la ciudadanía democrática. Miradas (11), 74-93.

Castells, M. (2005). La era de la información: Economía, sociedad y cultura. Vol 1. México: Siglo XXI.

Correa de Molina, C. (1997). Administración estratégica y calidad integral en las instituciones educativas. Bogotá: Editorial Magisterio.

García, G. (2014). Ética del cuidado de sí y desarrollo humano: Un reto para la Educación Superior. Revista lasallista de Investigación 11 (1), 125-132.

Gutiérrez, R. (1986). Sobre el sentido del estudio universitario. El anillo de Giges 3(4), 138-145. Recuperado de: file://C:/Users/user/Downloads/gutierrezgirardotrafael_sentidodelosestudios_\%20 (2).pdf

Lutsan, N. (2013). Features of the training of primary school teachers to work in a Multicultural Enviroment. Review of European Studies. Current Issues in some disciplines. ISBN 978-80-8969101-2. Vasyl Stefanyk Precarpathian National University, Ivano-Frankivsk. Ukraine. Recuperado de: http://www.irisro.org/inter2013angol/014NadiaLutsan.pdfç

Marcano, N. y Reyes, W. (2007). Categorías epistemológicas para el estudio de los modelos de 
formación docente. Multiciencias 7(3), 293-307.

Molina, J. (2015). Recorrido por dos ámbitos identitarios: Universidad y ciberespacio- Revista lasallista de Investigación. 12 (2), 204-214.

Morova, N. Kusnetsova, V. Lezhnina, L. Talanova, T. (2015). Ethnocultural and Social Dominants of Pedagogical Education in Conditions of National Region. Review of European Studies; Vol. 7 , No. ISSN 1918-7173 e-ISSN 1918-7181. Published by Canadian Center of Science and Education. Canadá.

Nussbaum, M. (2010). Sin fines de lucro. Por qué la democracia necesita de las humanidades. Buenos Aires: Katz Editores.

Oppenheimer. A. (2016). ¿Quién piensa en las artes y las humanidades? Semana. Recuperado de: http:// www.semana.com/cultura/articulo/andres-oppenheimer-las-ciencias-sociales-y-el-arte/481148

Pineda, D. (2010). El investigador pedagógico: Una perspectiva sherlockiana. Praxis \& Saber $1(1), 43-75$.

Platón (1991). Obras completas. Segunda edición. Madrid: Aguilar.

Quintana, J. (2009). Propuesta de una Pedagogía Humanista. Revista Española de pedagogía. Año LXVII, n 243, mayo-agosto, 209-230

Rivera, J. \& Polonia, J. (2013). Problematizar, proyectar, comprender y significar: Estrategias didácticas para la formación humanística desde las disciplinas. Revista Actualidades Pedagógicas. $N^{\circ} 61$ enero-junio del 2013, pp.77-93

Ruíz, J., Aguilar, N., \& Ramírez, E. (2008). La orientación socio-humanística. Un aporte a la formación integral del estudiante. Tendencias Pedagógicas (13), 175, 191.

Savater, F. (2010). El valor de educar. Primera edición. Editorial S. A. Madrid.

Soto, D. (2009). El profesor universitario de América Latina: Hacia una responsabilidad ética, científica y social. Rhela 13, 166-188.

Urrea, A. (2012). El papel de las humanidades en la educación. Opinión 5580. Periódico Crónica del Quindío. Recuperado de: http://www.cronicadelquindio.com/noticia-noticia_opinion-seccion

Zemelman, H. (2005). Voluntad de conocer. El sujeto y su pensamiento en el paradigma crítico. México: Anthropos. 